\title{
BNWL-194
}

$29-$

\section{STRESSES IN ZIRCALOY-2 CLADDING DURING VIBRATORY FUEL LOADING}

RESEARCH

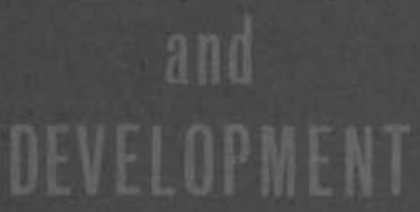

REPORT
R. L. GIBBY and R. J. LOBSINGER

MARCH, 1966 


\section{LEGAL NOTICE}

This report was prepared as an account of Government sponsored work. Neither the United States, nor the Commission, nor any person acting on behalf of the Commission:

A. Makes any warranty or representation, expressed or implied, with respect to the accuracy, completeness, or usefulness of the information contained in this report, or that the use of any information, apparatus, method, or process disclosed in this report may not infringe privately owned rights; or

B. Assumes any liabilities with respect to the use of, or for damages resulting from the use of any information, apparatus, method, or process disclosed in this report.

As used in the above, "person acting on behalf of the Commission" includes any employee or contractor of the Commission, or employee of such contractor, to the extent that such employee or contractor of the Commission, or employee of such contractor prepares, disseminates, or provides access to, any information pursuant to his employment or contract with the Commission, or his employment with such contractor.

PACIFIC NORTHWEST LABORATORY

RICHLAND, WASHINGTON

operated by

BATTELLE MEMORIAL INSTITUTE

for the

UNITED STATES ATOMIC ENERGY COMMISSION UNDER CONTRACT AT(45-1)-1830 


\section{9}

BNWL -194

UC-25, Metals, Ceramics, and Materials

STRESSES IN ZIRCALOY-2 CLADDING

DURING VIBRATORY FUEL LOADING

By

R. L. Gibby and R. J. Lobsinger

Materials Department

February, 1966

PACIFIC NORTHWEST LABORATORY

RICHLAND, WASHINGTON 
Printed in USA. Price $\$ 1.00$. Available from the Clearinghouse for Federal Scientific and Technical Information National Bureau of Standards

U. S. Department of Commerce Springfield, Virginia 


\section{STRESSES IN ZIRCALOY-2 CLADDING} DURING VIBRATORY FUEL LOADING

\section{INTRODUCT ION}

Although high energy vibratory compaction has proven to be an excellent means of loading reactor fuel rods with sized ceramic fuel powder, severe stresses $c$ an be generated in the rods by this method, resulting in cladding failures. This report discusses the results of a vibration test program conducted to investigate fatigue failures in Zircaloy-2 tubes. A number of fuel tubes cracked at the ends attached to the vibrator unit during vibratory loading of fuel rods for the Plutonium Recycle Demonstra-

tion Experiment in the EBWR.

Although most of the affected tubes did not crack completely, ultrasonic inspection revealed cracks in and/or near the end caps. Exposure of the defective tubes to a simulated in-reactor environment (thermal cycling in an autoclave) caused crack propagation. This action prompted a study to determine the mechanisms of cladding failure and to establish or recommend modifications in fabrication methods which might eliminate the problem.

\section{SUMMARY}

The vibratory fuel loading test program produced fatigue failures in the experimental tubes, which appeared to be identical to the failures experienced during fabrication of EBWR fuel rods. Electrodynamic vibrators were used to apply various resonance frequencies to five empty fuel tubes. Held in vertical positions in four different end clamp arrangements, the tubes were subjected to longitudinal vibrations until they cracked.
Stress measurements indicated that the use of a modified tapered clamp would transfer severe stresses from the end-cap crevice (the failure site) to the heavier and stronger cladding wall, thereby eliminating fatigue failure.

\section{EXPERIMENTAL PROCEDURE}

Tube Clamp Arrangements

The test specimens used for stress measurements were standard Zircaloy-2 EBWR fuel tubes (143.51* $\mathrm{cm}$ by 0.945 ID by $0.069 \mathrm{~cm}$ wall thickness) with one end-cap in place. The tubes were vibrated in a vertical position after attachment to an electrodynamic vibrator (Figure 1). Three end-cap clamps (Figure 2) were used during the experimient. The clamps were either attached directly to the vibrator top (direct coupling) or to a "resonance" plate assembly mounted on the vibrator. Clamps already welded to plates were bolted as a unit to the resonance plate. This arrangement is referred to as a "reinforced resonance plate."

\section{Electrodynamic Vibrators}

Experiments were conducted with two different electrodynamic vibrators. A Calidyne vibrator was used for studying vibration of empty tubes directly coupled to the shaker, while a C-20 M-B shaker was used for studying cladding stresses generated during actual fuel loading. (The $M-B$ shaker with resonance plate attached was used for production loading of the majority of EBWR fuel rods.) The Calidyne unit's frequency range of $0-2000 \mathrm{cps}$

* Length with end cap welded in place. 
had to be scanned manually and the applied force level of the shaker was varied with a noncalibrated rheostat. With an established frequency range of 230-1600 cps, the M-B vibrator can be adjusted to scan either manualy or at several fixed sweep rates from 0.4 octaves/sec to $\sim 0.06$ octaves $/ \mathrm{sec}$. Monitored with an accelerometer arrangement, applied forces of 10,20 , 30,40 , and $50 \mathrm{~g}$ were used at various stages of the investigation.

\section{Stress Measurements}

Stress patterns and stress magnitudes were measured with "stress coat" brittle lacquer which was applied and cured in the immediate vicinity of the test. It was applied both on $\mathrm{UO}_{2}-$ filled tubes and on empty tubes in order to analyze and compare stress patterns in each after vibratory treatment. After the stressing treatments, stress amplitudes were determined by measuring the number of cracks in the

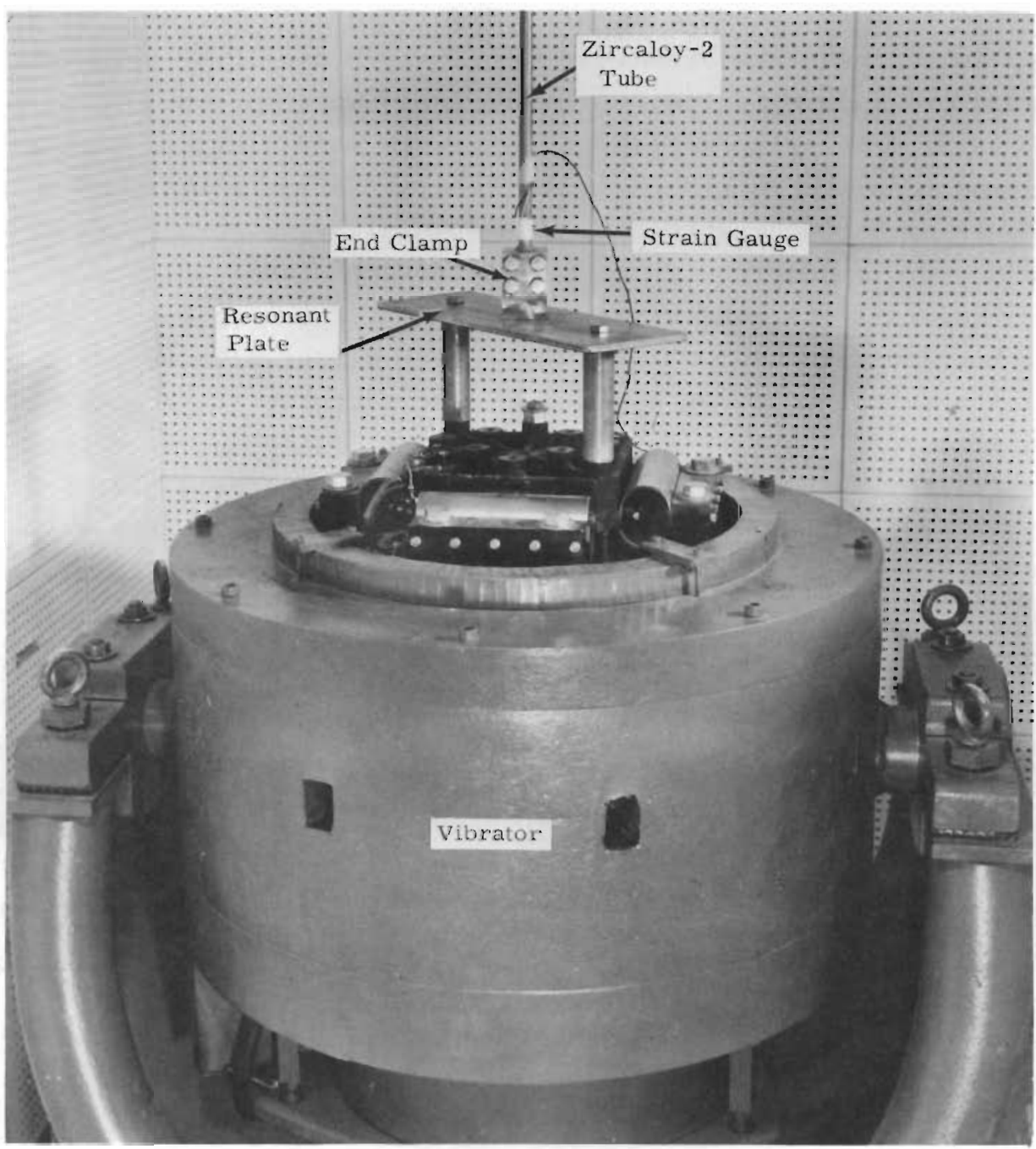

FIGURE 1. Vibration Test Apparatus Resonance Plate Arrangement 


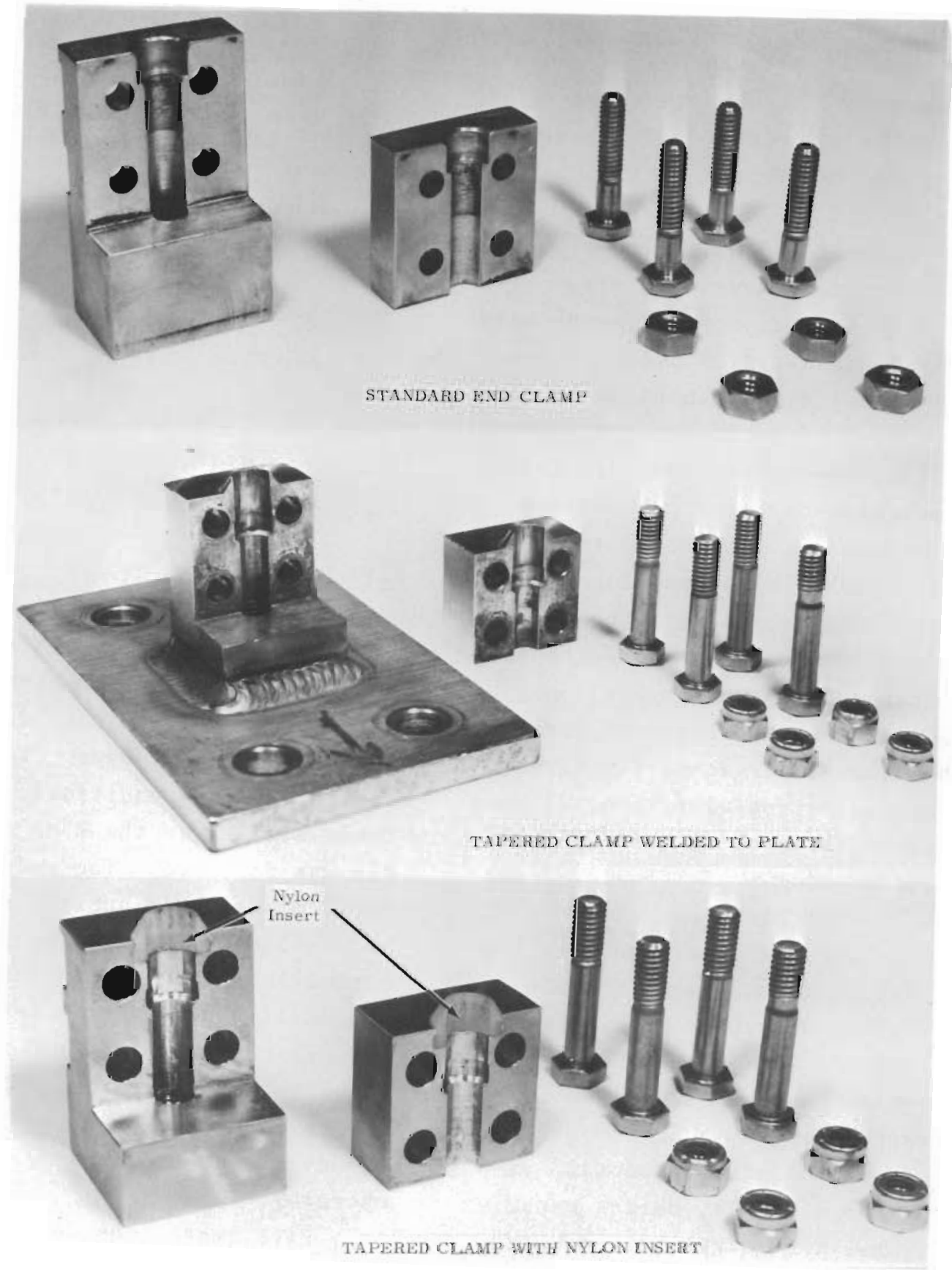

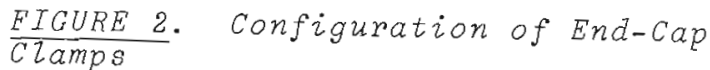


brittle lacquer per unit length and comparing this with a coating on a standard test bar subjected to known stresses. Stress magnitudes determined by the brittle lacquer measurements were on $1 y$ semiquantitative because of the unknown effect of sustained vibration on the 1 inear crack density.

In general, quantitative stress measurements were made with strain gauges. Metal film strain gauges (120 ohm resistance) were attached to the tubes with Eastman 910 adhesive. The soldered lead wire connections also had to be coated with cement to prevent fatiguing of gauge connections during vibration. Connected to a null balance circuit in an oscillograph, the strain gauges recorded the stresses directly on strip charts as a function of time and/or frequency. Stress values were calculated, assuming that the proportional limit was not exceeded during vibration. A room temperature value of $14 \times 10^{6} \mathrm{psi}$ (1) for Young's modulus of Zircaloy-2 was used in the calculations.

Some heat was generated near the strain gauges during oscillation but was not great enough to affect overall strain measurements. A variety of strain gauges and mounting orientations were employed to determine regions of maximum stresses during $v i-$ bration. As a result, during experimental runs, the gauges were mounted in the vicinity of the end clamp, since this region was demonstrated to be particularly susceptible to cracking. An empty fuel tube with a mounted strain gauge is shown in Figure 3 .

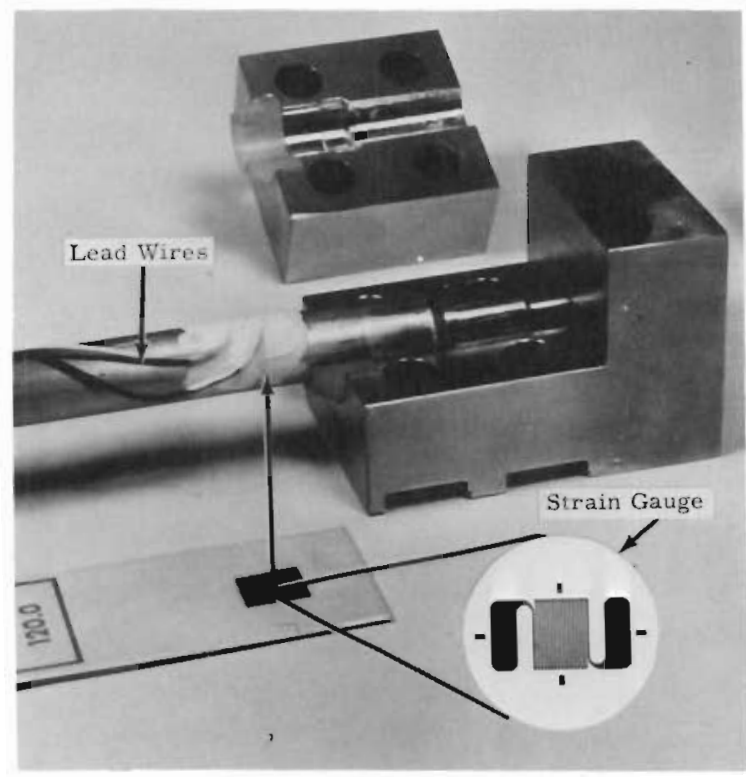

EIGURE 3. Strain Gauge Mounted on Fuet Tube

Fue] Loading

A sized EBWR $\mathrm{UO}_{2}-\mathrm{PuO}_{2}$ powder mixture consisting of 55 wt: $(-6+10$ mesh $), 25$ wt: $(-20+65$ mesh $)$, and 20 wt: (-200 mesh) was used during fuel loading stress studies. To ensure similar stress conditions, a loading cycle similar to the EBWR loading cycle was followed. The rods were loaded for 1 min each at applied shaker forces of 20,30 , and $40 \mathrm{~g}$. The shaker was automatically cycled in the frequency range 235-1600 cps at a sweep rate of 0.4 octaves/sec. After $3 \mathrm{~min}$ of loading, the rods were tamped for 1 min at an applied force of $50 \mathrm{~g}$. The frequency range was manually swept by the operator.

Five empty rods were shaken on the Calidyne vibrator at various resonance frequencies until they cracked. The rods were subjected to metallographic examination, and the results were compared with rod failures that occurred during fuel loading. 
RESULTS AND DISCUSSION

Longitudinal vibrations, imparted by an electrodynamic vibrator to the fixed end of a vertically held EBWR tube, excited natural transverse vibrational modes in the tube. At particular vibrator frequencies, transverse standing waves were established in the tubing. The standing waves were readily observed, since maximum tube deflections were normal to the tube axis and often exceeded $15 \mathrm{~cm}$ peak-topeak. After vibration at resonance frequencies, stress coat crack patterns on empty and filled tubes consisted of circumferential stress bands spaced at intervals between unstressed bands or nodes. The number of nodes depended upon the frequency at which resonance occurred. The severest stresses occurred near the fixed end of the tubes, with the stresses greater for filled tubes than empty ones. Stresses as high as 45,000 psi were calculated from the crack densities measured in the brittle lacquer coatings on empty tubes.

In some cases, torsional or twisting vibrational modes were excited in conjunction with the transverse vibrations. Under ideal conditions, generation of transverse or torsional vibration by longitudinal excitation is impossible; however, in a real system it is difficult to obtain only pure longitudinal vibrations; consequently, transverse and torsional components are present, in some cases to a greater extent than others. At the natural transverse or torsional vibrational modes of a tube, the transverse or torsional vibration components are amplified in the resonating tube. Solution of the wave equation for transverse vibration of a fixed-free tube gives the following equation for the allowed transverse vibration frequencies:

$$
v_{n}=\frac{\pi}{2 L^{2}} \sqrt{\frac{E k^{2}}{\rho}} B_{n}^{2}
$$

where $\beta_{n} \simeq(n-1 / 2), n \geq 2 ; \beta_{1}=0.597$

$$
\begin{aligned}
& \rho=\text { density }=\begin{array}{r}
6.55 \mathrm{gm} / \mathrm{cm}^{3} \\
Z \mathbf{r}-2
\end{array} \text { for } \\
& k= \text { radius of gyration } \\
&= 1 / 2 \sqrt{\mathrm{r}_{1}{ }^{2}+\mathrm{r}_{2}{ }^{2}}=0.112 \mathrm{~cm} \\
& \text { where } \mathrm{r}_{1}=\text { inside radius } \\
& \quad \mathrm{r}_{2}=\text { outside radius } \\
& L=\text { tube length }=138.2 \mathrm{~cm}^{*} .
\end{aligned}
$$

Table I presents the calculated values for the first 13 transverse vibrational frequencies of an EBWR tube. The transverse vibrational modes observed for one tube, with the corresponding longitudinal excitation frequencies, are also shown. These preliminary data do not give a simple correlation between applied longitudinal frequency and excited transverse frequency. Transverse modes are excited at different longitudinal frequencies for each of the two electrodynamic vibrators.

The possibility of resonance at natural longitudinal vibration modes was also considered. Solution of the wave equation for longitudinal vibration of a fixed-free tube yields the following frequency equation:

$$
\nu_{n}=\frac{(2 n-1) \pi C}{2 L}
$$

where $\mathrm{C}=$ longitudinal wave velocity

$$
\begin{aligned}
& =4.65 \times 10^{5} \mathrm{~cm} / \mathrm{sec} \\
L & =\text { tube length }=138.2 \mathrm{~cm} .
\end{aligned}
$$

* Tube length for top of end cap clamp. 


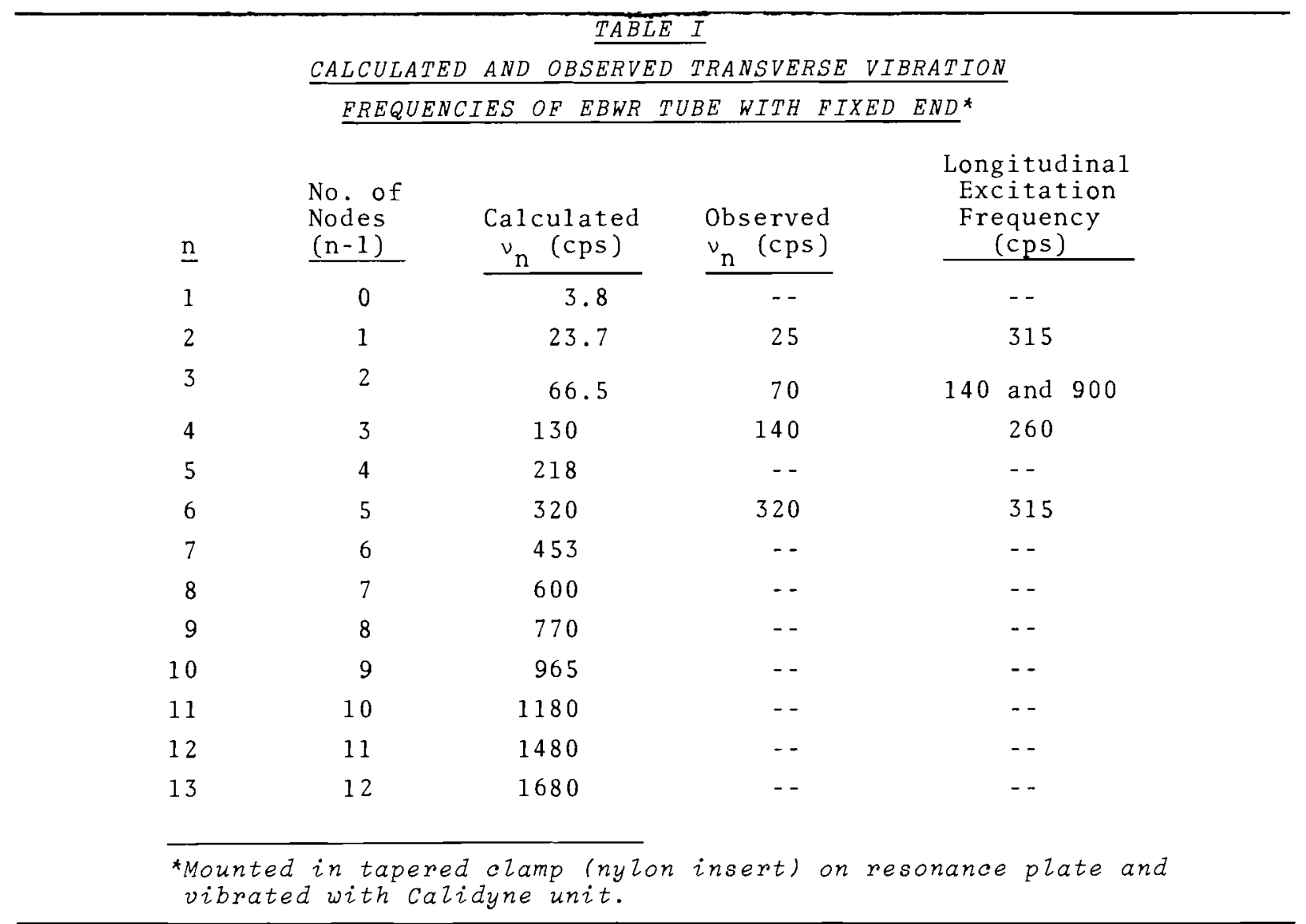

The calculated values for the first five natural longitudinal modes of an EBWR tube are given in Table II. The first natural mode at which resonance would occur is more than twice the highest frequency attained with either electrodynamic vibrator. Therefore, it was concluded that longitudinal resonance would not be expected unless the driving frequency was greatly increased.

Since flexing or bending stresses from transverse vibration were concluded to be the cause of fatigue failures, five empty tubes were vibrated at three resonating frequencies until failure occurred. With a standard clamp directly coupled to a Calidyne vibrator, the tube cracked in less than $10 \mathrm{~min}$ at a driving frequency of 600 cps. When a modified tapered clamp was substituted, tube 1 ife was extended to approximately $20 \mathrm{~min}$. When $\mathrm{MoS}_{2}$ powder was placed between tube and clamp, failure did not occur during $20 \mathrm{~min}$ of sustained vibration at a resonance frequency. The failed tubes were sectioned, and the cracked regions were subjected to metallographic examination. The fatigue failures in the experimental tubes appeared identical to the failures experienced during production of EBWR fuel rods, as illustrated in Figure 4.

By relocating severe stresses from the end-cap crevice region to the thicker tube wall, the modified tapered clamp was instrumental in extending tube 1 ife. Failures that did occur with the modified clamp were initiated 
TABLE II

LONGITUDINAL VIBRATION RREQUENCIES OF EBWR TUBE WITH EIXED END

Number of Nodes

$\begin{array}{ccc}n & \frac{(n-1)}{\nu_{n}(\mathrm{cps})} \\ 1 & 0 & \frac{\nu_{n}, 250}{25,710} \\ 3 & 1 & 15,240 \\ 4 & 2 & 36,740 \\ 5 & 3 & 47,240\end{array}$

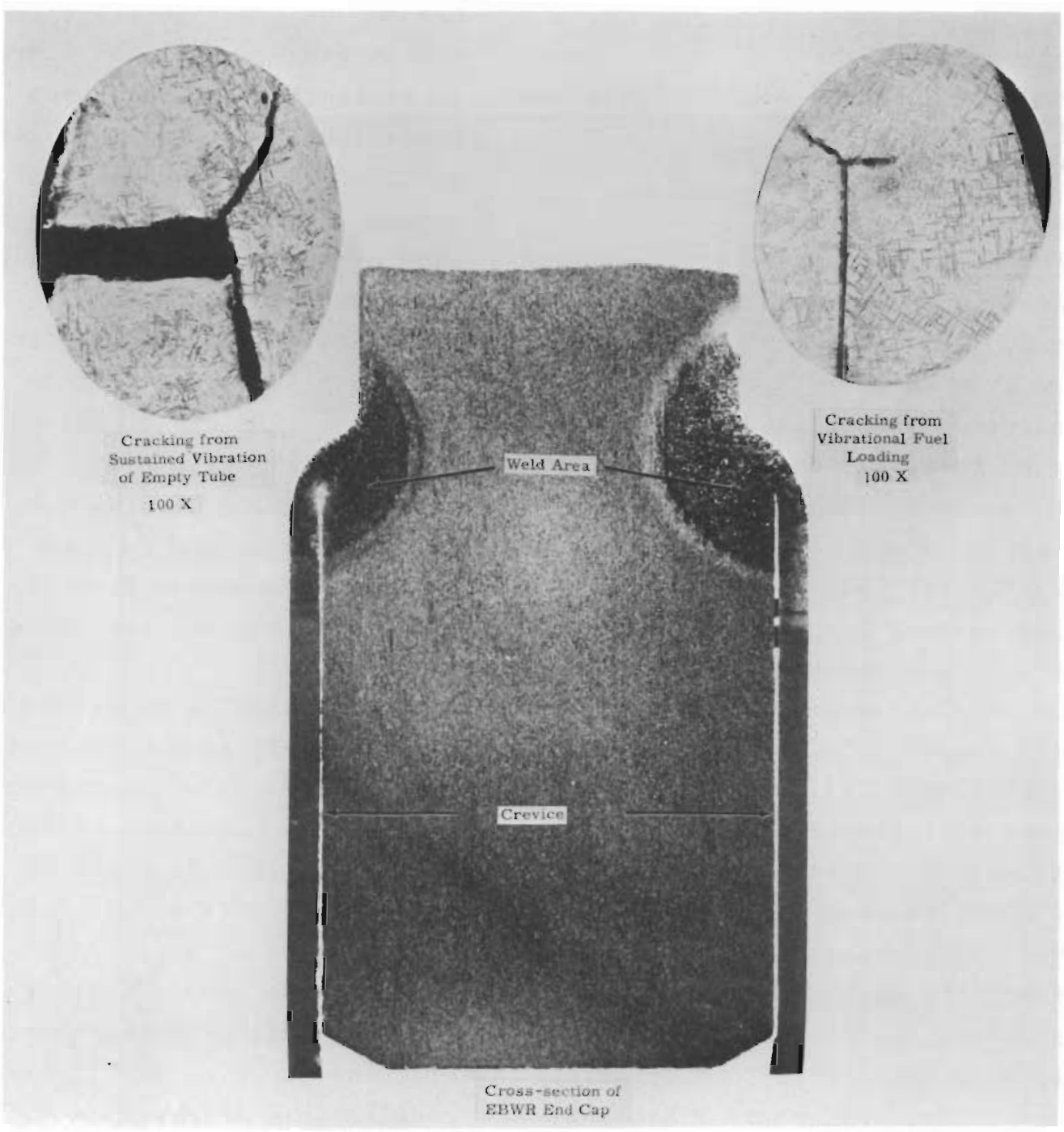

FIGURE 4. Fatigue Failures Produced Experimentalzy and during Fuel Loading of $E B W R$ Rod. 
at clamp fretting marks on the tube. The $\mathrm{MoS}_{2}$ powder was effective in reducing, temporarily, fretting action between tubing and clamp, thus further extending tube life during resonance vibration. Although the tapered clamp with nylon insert was not tested, it should be even more effective in reducing fatigue failures due to fretting. Stress measurements were obtained for empty tubes with the following clamp arrangements:

- Standard clamp, resonance plate

- Standard clamp, reinforced resonance plate

- Modified tapered clamp, reinforced resonance plate

- Modified tapered clamp with nylon insert, reinforced resonance plate.

For comparison, some of these data are shown in oscillogram tracings in Figure 5. The frequency range was scanned at a sweep rate of about 0.1 octaves/sec. The ordinate has been converted to stress by multiplying strain values by Young's Modulus for Zircaloy-2, Since the scan speed of the oscillograph was much slower than the tube flexing frequency, a stress envelope was recorded. Both tensional and compressional stresses were measured with the gauges. The symmetry of the stress envelopes indicate strain gauge alignment with the bending direction. In most cases, the stress envelopes are very symmetrical.

Modifications of the end clamp do not affect the magnitude of maximum stress values, but the stress-frequency relationship is altered considerably. In other words, transverse vibrations are excited at different frequencies when different clamps and clamping arrangements are employed.
Rotational orientation of the standard end-cap clamp on the resonance plate did not affect the stressfrequency pattern (Figure 6). Reinforcement of the resonance plate, when using a standard clamp, increased the integrated stress level but did not increase maximum stress values (Figure 5). The additional stresses are generated in the low frequency range.

When loading an EBWR tube with sized $\mathrm{PuO}_{2}-\mathrm{UO}_{2}$ powder, a design fatigue limit of $25,000 \mathrm{psi}^{3}$ is not exceeded, at least in the vicinity of the strain gauge, until the vibrator force level reaches $40 \mathrm{~g}$ (Figures 7 and 8 ). Since tubes have failed at lower applied force levels, it is probable that stress raisers exist in the crevice region of the end cap. Zircaloy- 2 weld metal is more notch-sensitive than the base metal ${ }^{(2)}$, and makes the weld area particularly susceptible to fatigue cracking. The use of the modified tapered clamp with nylon insert in production loading of EBWR fuel rod has eliminated fatigue failures by relocating severe stresses from the end-cap crevice to the heavier and stronger cladding wall.

The addition of oxide powder to a tube, as well as packing and densification of the powder in the tube, increases the magnitude of tube bending stresses. This is shown in the oscillogram in Figure 9, which displays successive frequency cycles at the same vibrator force level during fuel loading. The multitude of factors involved in the cracking process make it difficult to confirm this observation with simple bending stress calculations for empty and full tubes. 


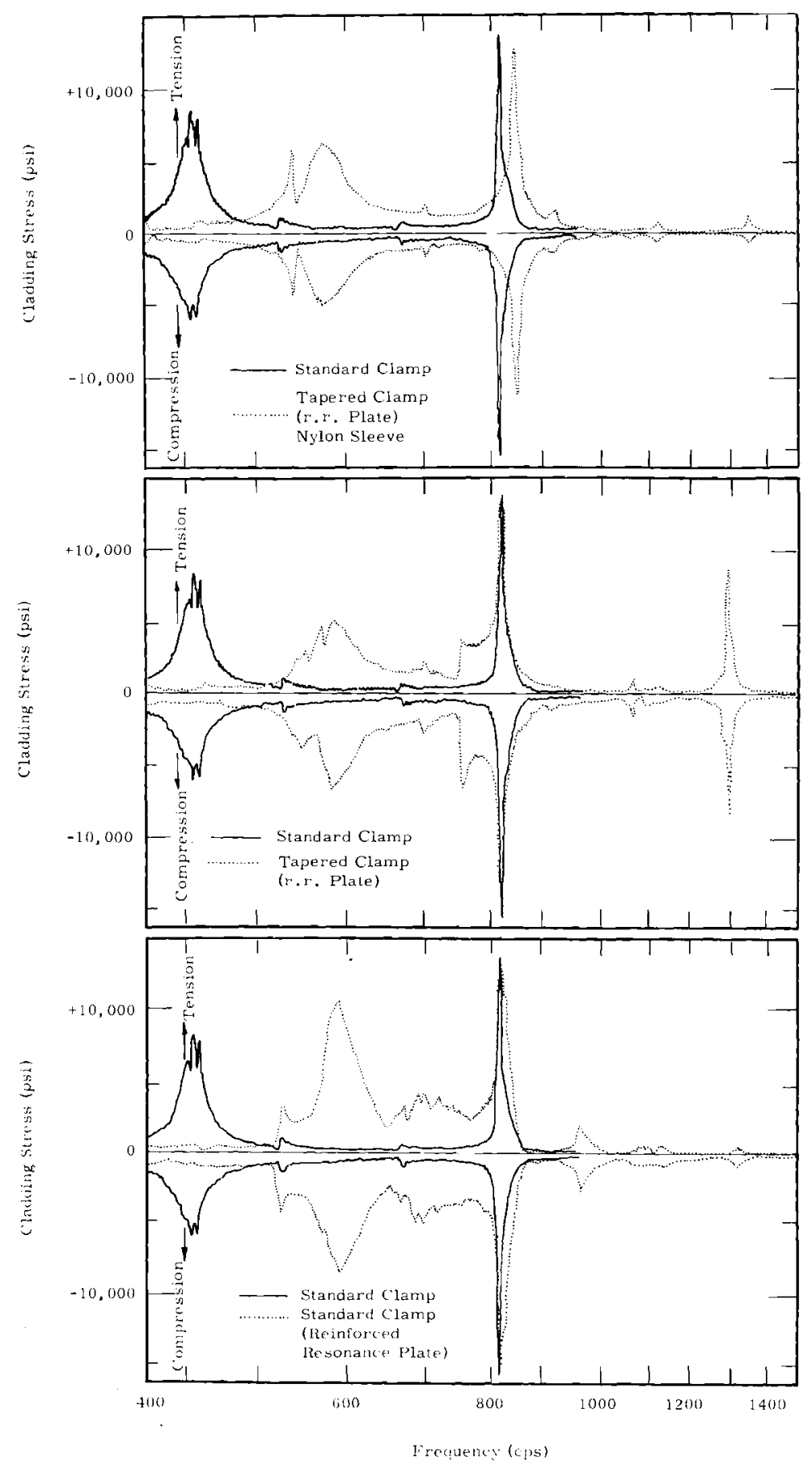

FIGURE 5. Stress Measurements of Empty Tubes with Different Clamps 
BNWL - 194

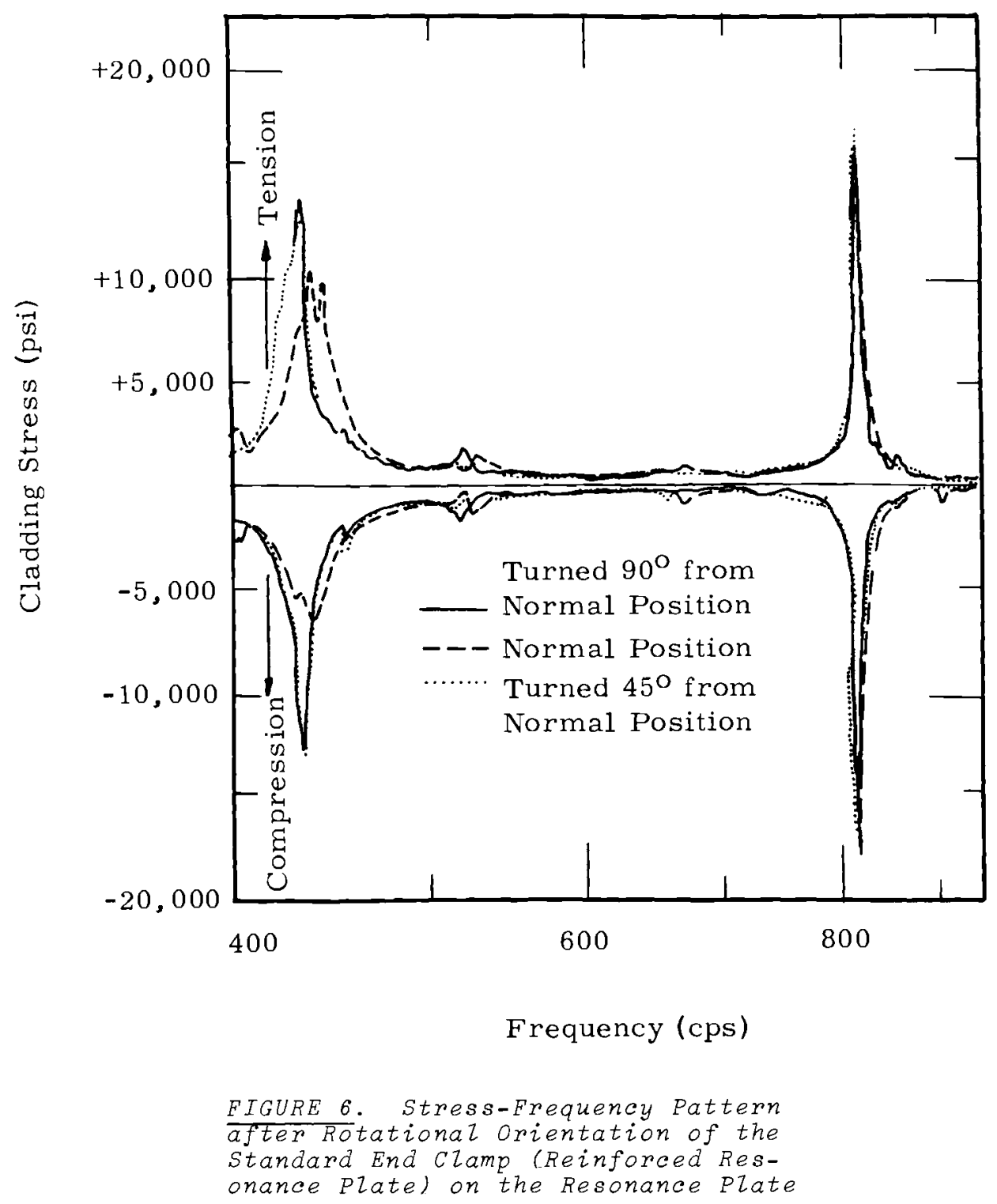

The greatest stresses were measured during tamping of a completely filled rod. At an applied force level of $50 \mathrm{~g}$, stresses as high as 70,000 psi were recorded during manual sweeping of the entire frequency range. At this stress level, calculations indicate that less than 1000 cycles could cause fatigue cracking. Assuming that the transverse resonance frequency at which this stress occurred was approximately
70 cps, then only 14 sec at this frequency could result in cracking and failure.

The longitudinal excitation frequencies for transverse vibration shift to lower values as the tubes are filled with powder (Figure 8). According to equation ( 1 ), the natural frequencies of the rod should be expected to change inversely with its density. Since the $\mathrm{UO}_{2}$ is present as an unbonded powder, 


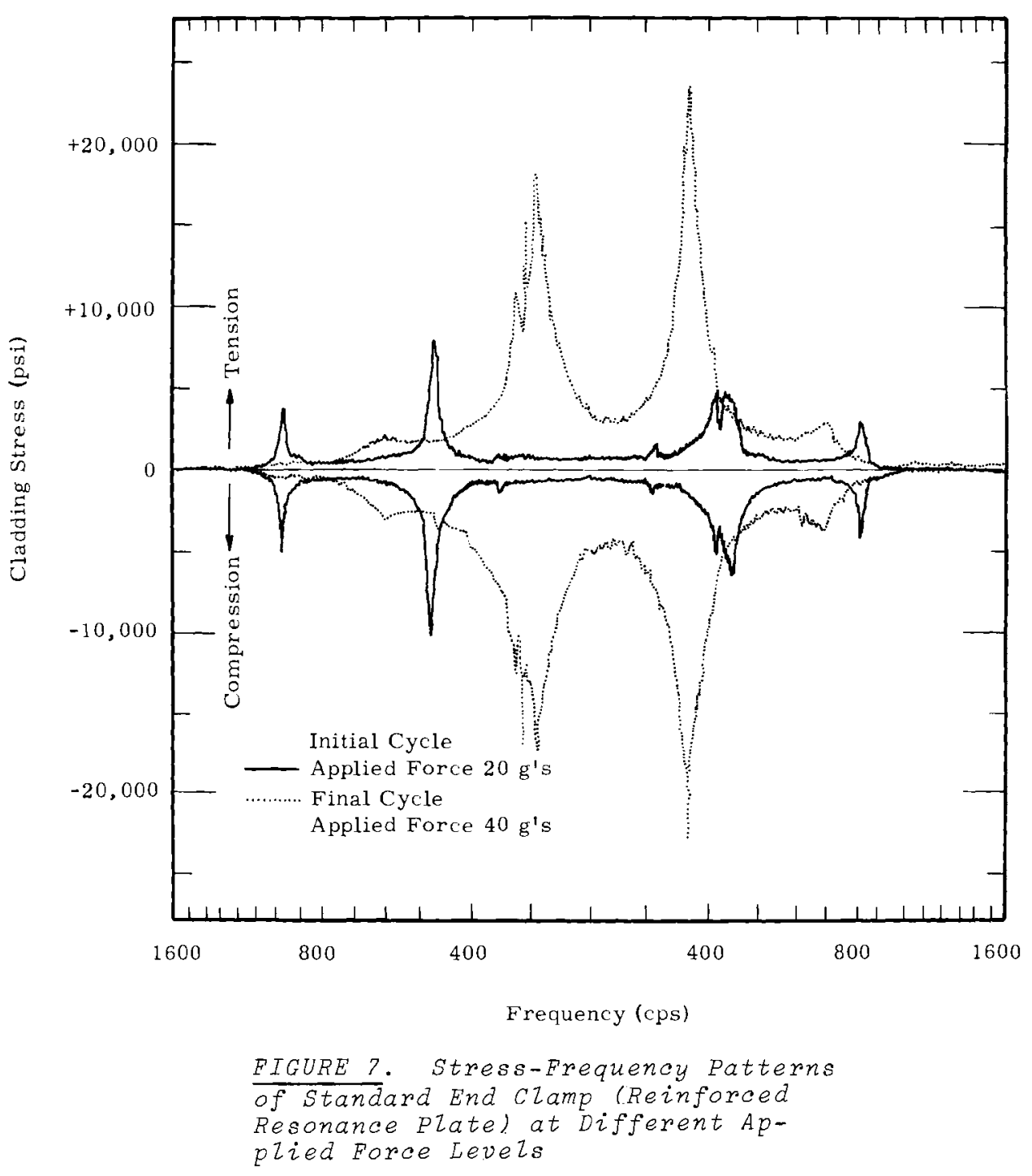

and assuming that the modulus of elasticity for the $\mathrm{UO}_{2}$ can be neglected, then the natural vibration modes of the fueled tube should occur at lower frequencies because of the increased density. This has not been confirmed experimentally, although it is strongly suggested by the observed shift in excitation frequency. Also shown in Figure 8 is the increase in number of excited bending modes at lower frequencies as the rods fill with fuel. The extra flexing action observed at low frequencies should not contribute to fatiguing because the stresses encountered are below the design fatigue limit.

\section{CONCLUSIONS}

Longitudinal vibration of EBWR tubes excites transverse vibrational mod-s in the tube. The stresses, measured with strain gauges located near the end clamp, are great enough to cause fatiguing of the Zircaloy-2 during the final stages of fuel powder loading. With a standard clamp, the 


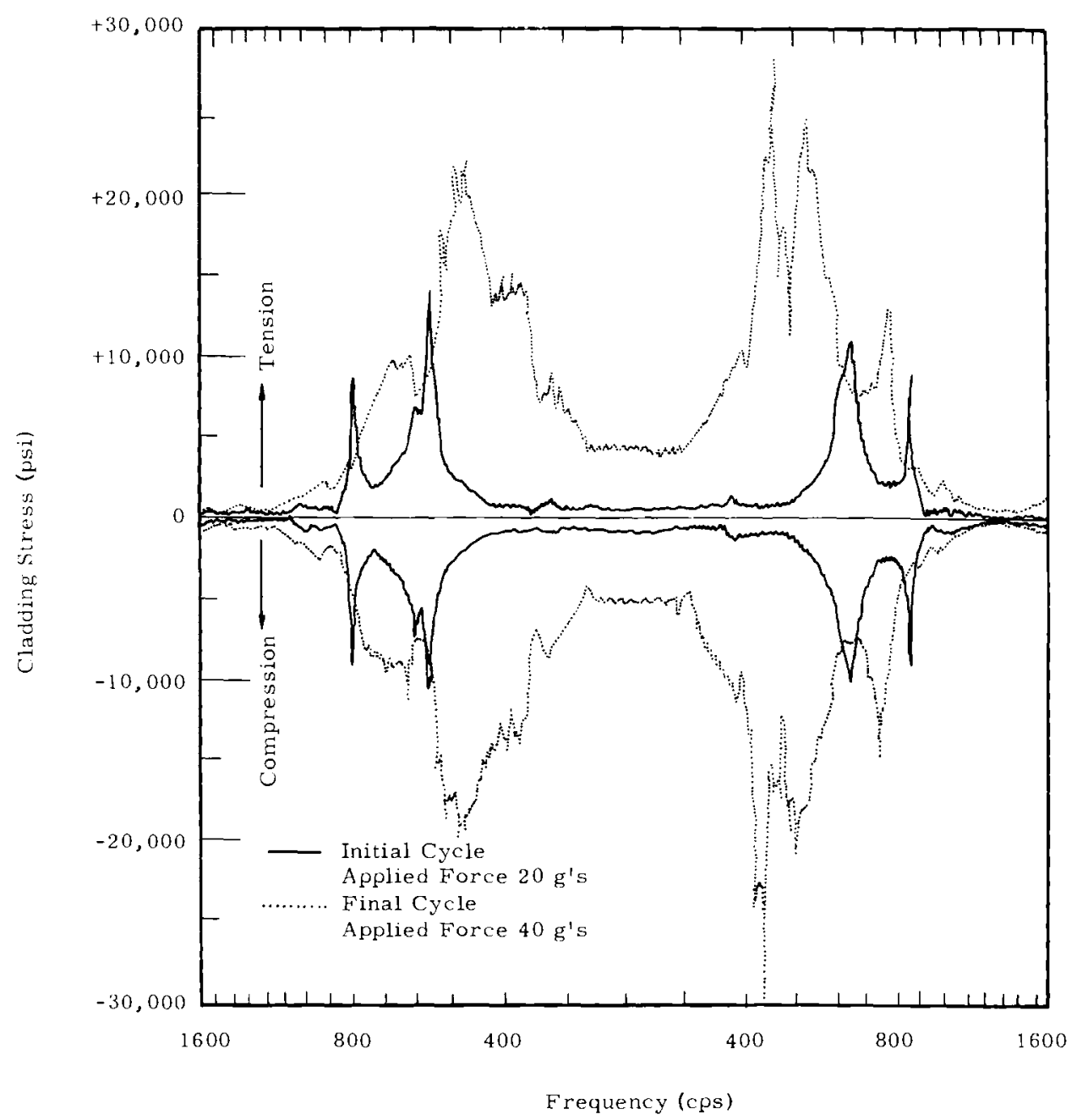

EIGURE 8. Stress-Frequency Pattern of Standard End Clamp (Reinforced Resonance plate) with Reinforced Resonance Plate at Different Applied Force Levels 


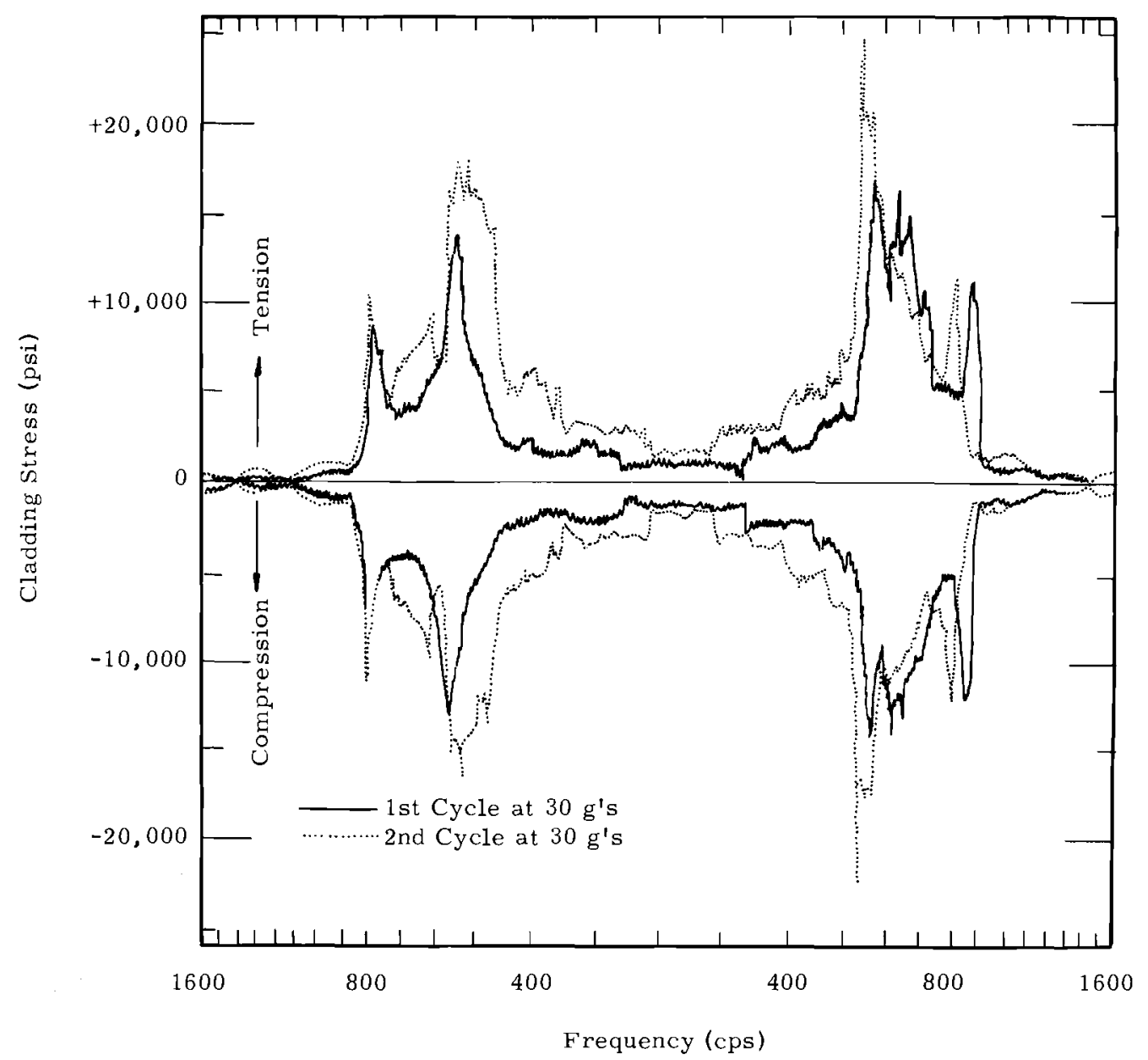

FIGURE 9. Successive Frequency Cycles of Standard End Clamp (Reinforced Resonance Platel. with Reinforced Resonance Plate at Same Vibrator Eorce Level

end-cap crevice acts as a stress raiser and fatigue failure can occur at lower stress values. By relocating major stresses to the heavier cladding, a modified tapered end clamp with nylon insert is very effective in reducing fatigue failures. Reinforcement of the resonance plate is undesirable because it increases the integrated fatigue stress level.

\section{ACKNOWLEDGMENTS}

The authors wish to express their gratitude to K. R. Merkx for his valuable recommendations on a suitable endcap clamp design.

\section{REFERENCES}

1. H. A. Salzer, R. F. Dickerson, and

E. L. Foster. Induction Melted $2 i r-$ caloy and zircaloy Alzoys, BMI-908, Battelle Memorial Institute. March $28,2954$. 
2. W. J. O'Donnelz. "Fatigue Notch Sensitivity of Zircaloy Weld Metal," Trans. Am. Nucl. Soc., vol. 7 , no. 2, pp. 454-455. 2964 .

3. W. J. O'Donnell and B. F. Langer. "Eatigue-Design Basis for Zircaloy Components," Trans. Am. Nucl. Soc., vol. 7, no. 2, pp. 224-225. 2964. 


\section{ONSITE DISTRIBUTION}

\section{Copy Number}

\begin{tabular}{|c|c|}
\hline & Pacific Northwest Laboratory \\
\hline 1 & R. E. Bardsley \\
\hline 2 & G. M. Dalen \\
\hline 3 & D. R. deHalas \\
\hline 4 & K. Drumheller \\
\hline 5 & P. L. Farnsworth \\
\hline $6-10$ & R. L. Gibby \\
\hline 11 & W. L. Hampson \\
\hline 12 & J. J. Hauth \\
\hline $13-17$ & R. J. Lobsinger \\
\hline 18 & R. E. Nightingale \\
\hline 19 & E. H. O'Claire \\
\hline 20 & R. E. Olson \\
\hline 21 & L. A. Pember \\
\hline 22 & W. E. Roake \\
\hline 23 & R. K. Robinson \\
\hline 24 & R. E. Sharp \\
\hline 25 & R. E. Skavdahl \\
\hline 26 & R. C. Smith \\
\hline $27-31$ & Technical Information Files \\
\hline $32-33$ & Technical Publications \\
\hline & Richland Operations Office \\
\hline 3 & P. G. Holstead \\
\hline . & R. K. Sharp \\
\hline 36 & Technical Information Libra \\
\hline
\end{tabular}

6

1 ALKEM

7501 Leopoldshafen

Karlsruhe, Germany

Attn: W. Stoll

5 Argonne National Laboratory

Attn: C. H. Bean

J . H. Handwerk

J. H. Kittel

R. Macherey

J. F. Schumar

1 Associazione EURATOM-CNEN

Per I Reattori Veloci

Via Mazzini 2

Bologna, Italy

Attn: F. Pierantoni
Atomic Energy Commission, Washington

Division of Reactor Development

Attn: R. Grube

J. M. Morrisey

F. C. Shwenk

J. M. Simmons

W. R. Voigt

M. J. Whitman

Atomic Energy Commission, Washington

Division of Research

Attn: W. F. Sheely

Atomic Energy Research

Establishment

Chemistry and Metallurgy Branch

Fuels Development Branch

Chalk River, Ontario, Canada

Attn: J.A. L. Robertson

Atomic Energy Research

Establishment

United Kingdom Atomic Energy

Authority

Harwell, Didcot, Berks, England

Attn: P. Murray (3)

L. E. Russe11(1)

Atomics International

Attn: B. R. Hayward

Atomic Power Development

Associates

119 First Street

Detroit 26, Michigan

Attn: W. H. Jens

A. A. Shoudy

Battelle Memorial Institute

Attn: D. L. Keller

S. W. Porembka (2)

W. F. Heenan (1)

Brookhaven National Laboratory Attn: D. H. Gurinsky

1 Centre d'Etudes Nucleaires de Cadarache

Poite Postale No. 1

Saint-Paul-Lez-Durance, France

Attn: Dr. B. Devreyn

1 Combustion Engineering, Inc.

Attn: J. C. Tobin

1 European Atomic Energy

Community

51-53 Rue Belliard (EURATOM)

Brussels 4, Belgium

Attn: Pierre Kruys

1 General Electric Company, APD

Special Purpose Nuclear Systems Operation

P. O. Box 450

Palo Alto, California

Attn: H. Miller 
General Electric Company, Cincinnati

Attn: E. A. Aitken

W. Briskin

J. McGurty

General Electric Company, Pleasanton

Attn: L. P. Bupp

E. A. Evans

A. I. Kaznoff

5

General Electric Company, San Jose

Attn: K. Cohen

A. N. Holden

T. J. Pashos

B. Weidenbaum

E. L. Zebroski

1 Kerr-McGee Industries, Inc.

Oklahoma City, Oklahoma

Attn: Harold Lambertus

1 Knolls Atomic Power Laboratory

Attn: W. K. Barney

5 Los Alamos Scientific

Laboratory

Attn: R. Baker

M. Bowman

H. Hessing

D. McMillan

R. Spence

2

NASA Lewis Research Center

Attn: A. F. Lietzke

N. T. Saunders

1 Transuranium Institute (EURATOM)

Karlsstrasse 42-44

Karlsruhe, Germany

Attn: H. M. Mattys

4 Union Carbide Corporation (ORNL)

Attn:

R. M. Carroll

J. L. Scott

W. C. Thurber

T. F. Connal1y

1 United Aircraft Corporation

Research Laboratory

East Hartford, Connecticut

Attn: G. H. McLafferty

1 University of Arizona

(Nuclear Eng ineering

Department)

Tucson, Arizona

Attn: Monte V. Davis

1 University of Michigan

College of Engineering

Ann Arbor, Michigan

Attn: W. Kerr

U. S. Atomic Energy Commission
2

Westinghouse Bettis Atomic

Power Laboratory

Attn: J. Belle

B. Lustman

$3 \quad$ Westinghouse Electric

Corporation

Attn: Robert Allio

A. A. Bishop

A. Boltax

1 Wright Air Development Center AF Materials Laboratory Wright-Patterson AFB

Dayton, Ohio

Attn: S. W. Bradstreet Brussels, Belgium

Attn: C. F. Schank 